\title{
Mireille Huchon, Louise Labé, une créature de papier
}

\section{Dario Cecchetti}

\section{Q OpenEdition}

\section{Journals}

\section{Edizione digitale}

URL: http://journals.openedition.org/studifrancesi/27398

DOI: 10.4000/studifrancesi.27398

ISSN: 2421-5856

\section{Editore}

Rosenberg \& Sellier

\section{Edizione cartacea}

Data di pubblicazione: 31 décembre 2006

Paginazione: $590-591$

ISSN: 0039-2944

\section{Notizia bibliografica digitale}

Dario Cecchetti, « Mireille Huchon, Louise Labé, une créature de papier », Studi Francesi [Online], 150 (L I

III) | 2006, online dal 30 novembre 2015, consultato il 08 novembre 2020. URL : http://

journals.openedition.org/studifrancesi/27398; DOI : https://doi.org/10.4000/studifrancesi.27398

\section{Questo documento è stato generato automaticamente il 8 novembre 2020.}

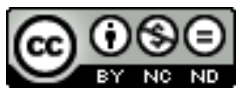

Studi Francesi è distribuita con Licenza Creative Commons Attribuzione - Non commerciale - Non opere derivate 4.0 Internazionale. 


\title{
Mireille Huchon, Louise Labé, une créature de papier
}

\author{
Dario Cecchetti
}

\section{NOTIZIA}

MIREILLE HUCHON, Louise Labé, une créature de papier, Genève, Droz («Titre courant», 34), 2006, pp. 483.

«L'existence de Louise Labé n'est pas en cause, même si elle ne fut qu'une femme de paille» (p. 275): con questa frase Mireille Huchon riassume, in parte, la sua ricerca, che da un lato potrebbe essere intitolata al 'mito' Louise Labé - mito smontato e analizzato nelle sue componenti -, dall'altro è una ricostruzione minuziosa di quanto gli strumenti della biblioteconomia - in questo caso impiegati nell'analisi dell'edizione delle Euvres del 1555 (di cui viene qui offerta la riproduzione anastatica nella sua integrità), negli aspetti testuali e paratestuali - forniscono circa il milieu in cui appare l'opera e il moltiplicarsi di esercizi letterari che coinvolgono poeti gravitanti intorno a Maurice Scève (Pontus de Tyard, Claude de Taillemont, Philibert Bugnyon, Guillaume de La Tayssonnière) e poeti legati alla Brigade, come Olivier de Magny o Jean-Antoine de Baïf. L'incertezza totale, concernente la Louise 'reale' e l'identità del suo amante (se mai è esistito, come pure la vita morale della poetessa, è ormai assodata, ed è evidente che si può parlare solo della printed Louise Labé (K. Cameron, 1990). Ed è proprio questo l'assunto di M. Huchon, che, riconoscendo la sopravvivenza «pour le lecteur moderne de cette Louise Labé imprimée», parte appunto dall'esame dell'imprimé, del libro a stampa del 1555 (tanto da identificare il personaggio Loïse Labé Lionnoise 1555 con l'edizione e la data), nella considerazione che «le Euvres de Louïe Labé Lionnoize sono un laboratorio, in cui si elabora, in questa metà del secolo così ricca di sperimentazioni formali, una vera arte poetica, con giochi sottilissimi, parodici», nella convinzione anche, peraltro ormai acquisita dalla critica, che «si tratta di un testo artificiale, molto lontano da quegli accenti di sincerità e autenticità assoluta che si era creduto di ritrovarvi» (p. 274). In effetti, dopo aver brevemente ripercorso gli scarsi dati 
documentari sulla vita di Louise e rievocato di scorcio il mito della Belle Cordière, M. Huchon dichiara i suoi intenti: «invece di rivolgere l'attenzione al suo ipotetico cenacolo, dove si sarebbero incontrate le più grandi menti del tempo, invece di ricostituire la biografia di Louise attraverso gli scritti poetici dovuti alla sua penna o attraverso quelli dei suoi pretesi amici, cui si vorrebbe accordare forza di verità a scapito della libertà di finzione, è molto meglio esaminare, nel loro contesto e senza a priori, le voci dei contemporanei e la sola traccia che ci sia rimasta delle attività letterarie di Louise Labé, vale a dire il libro pubblicato da Jean de Tournes» (pp. 11-12). L'indagine di M. Huchon, pertanto, è axée sugli Escriz de divers poëtes à la louenge de Louize Labé Lionnoize. Collocati in appendice alle opere (in un rapporto quantitativo del trenta per cento), questi Escriz constano di ventiquattro componimenti, per lo più anonimi (ma la paternità può quasi sempre essere riconosciuta): se li si considera un primo tentativo di ricostruzione della vita intellettuale della poetessa, è di qui che risulta l'immagine di una cortigiana ben integrata nei cenacoli lionesi e ammirata per la bellezza come per gli scritti. Ma più che per la ricostruzione dell'immagine di Louise, questi Escriz valgono per la restituzione del circolo che faceva perno sull'atelier dell'editore Jean de Tournes. In questa prospettiva, la dotta e sottile indagine dell'A. si sviluppa in tre successive sezioni, consacrate la prima (Magnificences de Lyon et fureur poétique au milieu du siècle, pp. 15-69) a rievocare l'ambiente lionese e i rapporti e scontri che lo animano; la seconda (Images de Louise Labé, pp. 71-139) a ritrovare le rappresentazioni - letterarie, ma anche iconografiche - della poetessa, a partire da quel ritratto di Pierre Woeiriot del 1555, madello per una serie di incisioni; la terza (Les dessous d'une supercherie littéraire: hommes et textes, pp. 141-270), senza dubbio la più importante, attraverso una disamina accurata degli Escriz, ma anche attraverso una ricognizione della cultura lionese (in primis degli entourages di Maurice Scève e Jean de Tournes), ricostruisce l'intrecciarsi delle forme letterarie e dei generi intorno e a partire dai testi delle Euvres, illustrando soprattutto come intorno a Louise Labé personaggio, mito o pretesto - si sviluppi un gioco letterario, che oscilla fra la mistificazione voluta e l'esercizio erudito. 